ISSN:2528-9527

E-ISSN : 2528-9535

YIl Year: 7

Cilt Volume:7

Sayı Issue : 12

Uluslararası Toplum Araştırmaları Dergisi

International Journal of Society Researches

Haziran June 2017

Makalenin Geliş Tarihi Received Date: 23/02/2017

Makalenin Kabul Tarihi Accepted Date: 30/05/2017

\title{
Bilinçli Farkındalık Temelli Bilişsel Terapi Programının Üniversite Öğrencilerinin Kaygı Düzeylerine Etkisi
}

\author{
$\underline{\text { Volkan Demir }^{*}}$ \\ * Psikoloji Uzmanı. Klinik ve Adli Psikoloji Derneği: Mecidiyeköy Mah. Kervangeçmez Cad. \\ Hark Sok. No:5 Kat:4. Şişli/İstanbul/Türkiye \\ E-Posta: demir.volkan@outlook.com \\ ORCID: 0000-0002-8148-8647
}

Öz

Bu çalışma bilinçli farkındalık temelli bilişsel terapi programının üniversite öğrencilerinin kaygı düzeylerine etkisini saptamak amacıyla hazırlanmıştır. Araştırma, İstanbul'da psikoloji bölümünde ikinci ve ü̧̈üncü sinıflarında öğrenim görmekte olan 16 öğrencinin katılımıyla gerçekleşmiştir. Araştırmada katılımcilara sekiz oturumdan oluşan her oturumu 90 dakika süren bir program uygulanmıştır. Katılımcıların kaygı düzeylerini belirlemek amacıyla Beck tarafından geliştirilen "Beck Anksiyete Envanteri" uygulanmıştır. Araştırmaya kabul ölçütleri; uygulanan Beck Anksiyete Envanteri puan sonuçlarma göre 'Orta' ve 'Şiddetli' düzeyde puan ortalaması olan ve çalışmaya katılmayı kabul eden öğrenciler olarak belirlendi. Ölçme araçları uygulama öncesinde ön test, uygulamanın bitiminde ise son test olarak uygulanmıştır. Tek grup öntest - sontest kontrol grupsuz yar deneysel desenin kullanıldığı çalışmada veriler, Wilcoxon İşaretli Sıra Testi ile çözümlenmiştir. Yapılan analizler katılımcıların kaygı puanlarının anlamlı düzeyde azaldığııı göstermiştir. Sonuç olarak, bilinçli farkındalık temelli bilişsel teknikler kullanılarak yapılan terapi programını uygulama yapılan öğrencilerin kaygı düzeylerinin düşmesine sebep olduğu gözlenmiştir.

Anahtar Kelimeler: Bilinçli farkındalık, Bilişsel terapi, Kaygı, Üniversite öğrencileri. 


\title{
Effects of Mindfulness Based Cognitive Therapy on the Anxiety Levels of University Students
}

\begin{abstract}
This study is aimed to analyse the effects of Mindfulness Based Cognitive Therapy on the anxiety levels of university students. Sample group is composed of 16 students who are in second grade or third grade in psychology department. A program is applied to the sample group, which is composed of 8 sessions, and each session were 90 minutes. "Beck Anxiety Inventory" is applied to comprehend the anxiety levels of sample group. After the application of Beck Anxiety Inventory, according to the results, individuals who have a "medium" or "severe" anxiety and also who confirms to attend the study are chosen. Measurement methods are applied as pre-test, before the application, and post-test after the application. Wilcoxon Signed-Rank Test is used for the analyse of one group pre-test posttest quasi-experimental design. Anaylses show that there is a significant decrease in the participants anxiety levels. Results are, the therapy program which is conducted by using mindfulness based cognitive techniques; causes a significant decrease in the anxiety levels of university students in the sample group.
\end{abstract}

Key Words: Mindfulness, Cognitive therapy, Anxiety, University students. 


\section{Giriş}

Kaygı bilişsel, somatik, duygusal, davranışsal bileşenleri olan ruhsal ve fizyolojik bir durumdur. Bu bileşenler tipik olarak huzursuzluk, kaygı, korku ve endişe ile ilişkili hoş olmayan bir duyguya neden olurlar. Genellikle tetikleyici bir unsurun tanımlanamadığ özelliği ile gözlenebilen bir tehlikenin varlığında ortaya çıkan korkudan ayrılır. Korku, kaçma ve sakınma gibi özgün davranış örüntüleri ile ilişkiliyken, kaygı kaçınılamaz ve kontrol edilemez olarak algılanan bir tehdit algisının sonucudur (Ohman, 2000). Beck ve Emery'ye (1985) göre tehdit edici bir uyaran ile karşı karşıya kalma durumunda yapılan bilişsel değerlendirmeye korku, bu değerlendirmeye verilen duygusal tepkiye ise kaygı denmektedir. Kaygının patolojik olduğuna karar verebilmek için zamanla azalmak yerine artması ve klinik tabloya ağırlıklı olarak baş dönmesi, kulak çınlaması, ağız kuruluğu, çarpıntı, nefes darlığı, çeşitli ağrılar, kas güçsüzlügü, yorgunluk gibi fiziksel belirtilerin hakim olması gerekir (APA, 2000). Süreğenleşmiş, bireyin işlevselliğini bozan, mesleki ve ailevi yaşantısını olumsuz yönde etkileyen, sosyal ilişkilerinde bozulmalara neden olan kaygı durumları patolojik olarak değerlendirilmelidir (Stahl, 2013). Kaygı, son yıllarda kuşku, bıkkınlık, zihinsel çatışma, hayal kırıklığı, mahcubiyet ve gerçek dışılık hissi gibi duygusal durumları ifade etmek için de kullanılmaktadır (Barlow, 2002).

Bilinçli farkındalık (mindfulness) kavramı son yıllarda artan bir şekilde bilimsel araştırma literatürünün ilgisini çekmektedir (Bao, Xue ve Kong, 2015; Wang ve Kong, 2014). Bilinçli farkındalık, alanyazında bir kuramsal yapıyı betimlemekle birlikte farkındalık geliştirme amaçlı yapılan bir uygulama anlamında (örn., meditasyon) ve psikolojik bir süreç olarak da (bilinçli farkında olma) kullanılmaktadır (Germer, Siegel ve Fulton, 2005). Bishop ve arkadaşları (2004) farkındalığın meditasyon temelli uygulamalar ile geliştirilebilen bir psikolojik süreç olduğunu ve bu olgunun işe vuruk tanımının yapılmasının psikoloji alanyazını için de önemli olacağını ifade etmişlerdir. Farkındalık kavramı en çok Budist psikolojisinde kullanılmasına rağmen kadim Yunan felsefesi, Amerika'daki hümanizm, Batı Avrupa öğretisindeki doğalcılık ve varoluşçuluk gibi bazı felsefi ve psikolojik geleneklerden gelişen fikirlerle kavramsal akrabalığı vardır (Brown, Ryan \& Creswell, 2007). 
Bilinçli farkındalık (mindfulness), geçmişte yaşanan veya gelecekte planlanan olası deneyim ve duyguların etkisi altında kalmadan anı kabul edip onaylamak şeklinde tanımlanır (Bishop ve ark. 2004). Bilinçli farkındalık kişinin o ana yani şimdiki zamana dikkatini yoğunlaştırıp, yargısız bir şekilde kabullendiği anlık deneyimdir (Kabat-Zinn 2005). Bilinçli farkındalık temelli terapiler, farkındalık düzeyini yükselten çeşitli tekniklerin ve alıştırmaların kullanıldığ terapi yöntemidir. Bu yöntemin uygulanması ile beraber kişi sorunlarla başa çıkma, içsel ve dişsal deneyimleri kabullenme ve uzaklaşma stratejilerini öğrenir (Hayes, Luoma, Bond, Masuda, \& Lilis, 2006). Bu terapiler, psikolojik rahatsızlıklara yol açan yaşantıların değiştirilmesini değil kabullenilmesini önermektedir (Siegel ve ark. 2009).

Farkındalık çok eski bir Budist uygulamasıdır. Kim olduğumuzu incelemekle, dünyayı ve dünyadaki yerimizi nasıl gördügümüzü sorgulamakla ilgilidir. Bilişsel terapiler kaynağını Budizm'den alarak "dünyayı düşüncelerimizle oluştururuz" görüşü ile temellerini oluşturur. Bilişsel terapiler de Budizm gibi, bireylere düşüncelerinin nasıl ortaya çıktığı, belli türdeki bazı düşünce ve istekleriyle başa çıkmak için zihinlerini nasıl eğitecekleri konusunda yol gösterir (Özyeşil, 2011). Farkındalık uygulamaları ile bilişsel-davranışçı terapiler, üstbiliş, duygu düzenleme, dikkat düzenleme konusunda benzer bir bakış açısına sahiptir (Çatak ve Ögel, 2010). Bilinçli farkındalık son zamanlarda artan biçimde, sıklıkla bilişsel ve davranışsal terapilere ek olarak klinik psikolojide kullanılmaktadır (Cash ve Whittingham, 2010).

Bishop (2004), bilinçli farkındalığın iki bileşeni olduğunu ifade eder. Bunlardan bir tanesi, dikkatin öz-düzenlenmesi (kendinden ayarlanması), ikincisi ise anlık deneyim sırasında yaşanan merak, kabullenme ve açık olma kavramlarının oryantasyonudur. Bilinçli farkındalığın bu bileşenler dışındaki önemli ve temel unsuru şimdiki zamanı yaşamanın rolüdür. Hatta bu, bilinçli farkındalığın kabul edilen en temel ve önemli özelliğidir. Birey, geçmiş yaşantılarına veya geleceğine odaklanma eğilimde ise, geçmiş yaşantılarının ve gelecekteki olası yaşantıların getirisi olan stres faktörleri ile daha çok iç içedir. Bu esnada deneyimlenen stres faktörleri kayg1 gibi sonuçlar doğurabilmektedir (Kabat-Zinn, 2003). Vøllestad, Sivertsen ve Nielsen (2011) kaygı bozukluğu olan hastalar için farkındalık temelli stres azaltma programının etkisini araştırmışlardır. Sekiz oturum 
farkındalık temelli stres azaltma programının kaygı bozukluklarında etkili bir tedavi olduğu sonucuna varılmıştır. Kaygı bozukluğu olan hastalar için farkındalık temelli stres azaltma programının etkinliğini belirlemek amacıyla yapılan diğer bir çalışmada katılımcıların program sonrası kaygı ve depresif belirtilerinde anlamlı ölçüde azalma gözlenmiştir (Peterson ve Pbert, 1992). Yook ve arkadaşları (2008) kaygı bozukluğu olan hastalarda uykusuzluk belirtilerini tedavi etmek için farkındalık temelli bilişsel terapi programının etkisini incelemişlerdir. 19 hastaya uygulanan sekiz haftalık program sonunda kaygı bozukluğuyla ilişkili uykusuzluk belirtilerinin azalmasında farkındalık temelli bilişsel terapinin etkili olduğu görülmüştür.

Bilinçli farkındalık temelli uygulamalar son 20 yılda artmış ve çoğunlukla iyi sonuçlar alınmıştır (Walsh ve ark. 2008). Bilinçli farkındalık temelli grup uygulamaları sağlık alanında da yaygın bir şekilde kullanılmaya başlanmış, araştırmalar hemşireler (Cohen-Katz ve ark. 2005, Mackenzie ve ark. 2006, Kemper ve ark. 2011), kanser hastalar1 (Smith ve ark. 2005, Witek-Janusek ve ark. 2008, Matchim ve ark. 2011, Tsang ve ark. 2012), madde kullanımı olan bireyler (Kristofersson, 2012) organ nakilli hastalar (Gross ve ark. 2010), diyabet hastaları (Whitebird ve ark. 2009), ve ailesine bakım veren bireyler (Whitebird ve ark. 2013) üzerinden yürütülmüştür. Yapılan çalışmalarda; kaygı ve davranış problemlerinde azalma (Semple, Lee, Dinelia ve Miller, 2010), sosyal becerilerde ve akademik performansta artış (Beauchemin, Hutchins ve Patterson, 2008), depresyon belirtilerinde azalma (Demir, 2014; Demir, 2015a; Demir, 2015b; Liehr ve Diaz, 2010), iyimserlik ve pozitif duygularda önemli seviyelerde artış, muhalif davranışlarda, saldırganlıkta azalma ve çocukların sosyal ve duygusal yetkinlik durumlarında iyileşme (SchonertReichl ve Lawlor, 2010), farkındalıkta artış (Huppert ve Johnson, 2010), sakinlikte, duygusal düzenleme, kendini kabul, rahatlama, farkındalık ve netlikte artış (Broderick ve Metz, 2009) olduğu tespit edilmiştir.

Buraya kadar yapılan açıklamalar göz önünde bulundurulduğunda, farkındalık temelli terapilerin psikolojik iyi oluş üzerindeki olumlu etkileri görülmektedir (Carmody ve Baer, 2009; Pinquart \& Teubert, 2010; Visted, Vøllestad, Nielsen \& Nielsen, 2015). Elde edilen bilgiler sonucunda, yapılan bu çalışmanın, üniversite öğrencilerinin kaygı düzeyleri 
üzerinde bilinçli farkındalık temelli bilişsel terapi programının etkisinin olup olmadığını belirlemeye katkıda bulunacağı düşünülmektedir.

\section{Araştırmanın Amacı}

$\mathrm{Bu}$ araştırmanın temel amacı, psikososyal müdahalelerden biri olan bilinçli farkındalık temelli bilişsel terapi programının üniversite öğrencilerinin kaygı düzeyleri üzerindeki etkisini incelemektir. Bu genel amaca dayalı olarak araştırmanın problem cümlesi şu şekilde belirlenmiştir.

\section{Problem Cümlesi}

Bilinçli farkındalık temelli bilişsel terapi programı üniversite öğrencilerinin kaygı düzeylerini azaltmada etkisi var mıdır?

\section{Yöntem}

\section{Araştırma Deseni}

Araştırmada, deneme modellerinden "Tek grup öntest - sontest kontrol grupsuz yarı deneysel desen" kullanılmıştır. Tek grup öntest - sontest modelinde gelişigüzel seçilmiş bir gruba bağımsız değişken uygulanır. Tek grup öntest - sontest modelinde hem deney öncesi (öntest) hem de deney sonrası (sontest) ölçmeler vardır (Karasar, 2014).

\section{Tablo 1: Araştırmanın Deseninin Sembolik Görünümü}

\begin{tabular}{lllc}
\hline Grup & Öntest & İşlem & Sontest \\
$\mathrm{G}$ & $\mathrm{O} 1$ & $\mathrm{X}$ & $\mathrm{O} 2$ \\
\hline
\end{tabular}

\section{Katılımcılar}

Araştırma Klinik ve Adli Psikoloji Derneği'nde gerçekleştirilmiştir. Araştırmanın örneklemi, 2015-2016 öğretim yılı bahar döneminde, psikoloji bölümünde öğrenim görmekte olan ikinci ve üçüncü sınıf öğrencileri arasından seçilen öğrencilerden oluşmaktadır. Çalışma grubu 11 kadın 5 erkek olmak üzere 16 öğrenciden oluşmaktadır. Bu öğrenciler 19- 
21 yaşları arasında bulunmaktadır. Kronik fiziksel hastalığı olan, psikiyatrik tedavi alan (ilaç ve/veya terapi), madde bağımlılı̆̆ı, intihar girişimi veya kendine zarar verme öyküsü olan öğrencilerin çalışmaya alınmamasına dikkat edilmiştir. Araştırmaya kabul ölçütleri; uygulanan Beck Anksiyete Envanteri puan sonuçlarına göre 'Orta' ve 'Şiddetli' düzeyde puan ortalaması olan ve çalışmaya katılmayı kabul eden katılımcılar olarak belirlendi. Beck Anksiyete Ölçeği'nden yüksek puan alan 38 öğrenci görüşmeye davet edilmiştir. Davet edilen öğrencilerden 29 öğrenci ön görüşmeye katılmıştır. Katılımcılara araştırmanın amacı ve grup çalışmasının özellikleri konusunda bilgi verilerek katılımın gönüllülük ilkesine dayandığı açıklanmış ve onam alınmıştır. Çalışmaya katılanların kişisel bilgilerinin başkalarına açıklanmayacağı konusunda güvence verilmiştir.

\section{Veri Toplama Araçları}

Sosyodemografik Bilgi Formu: Katılımcilara verilen bu form sosyodemografik özellikleri sorgulamak amacıyla araştırmacı tarafından hazırlanmıştır. Bu form ile yaş, cinsiyet, eğitim düzeyi, medeni durum, meslek, kullanılan ilaç tedavileri, alkol-madde kullanımı ve diğer fiziksel hastalıkları sorgulanmıştır.

Beck Anksiyete Ölçeği: Bireylerin yaşadığı kaygı belirtilerinin sıklığının belirlenmesi amacı ile Beck ve arkadaşları tarafından 1988 yılında geliştirilen, 21 maddeden oluşan ve 0-3 arası puanlanan bir kendini değerlendirme ölçeğidir. Türkçe geçerlilik ve güvenilirlik çalışması, Ulusoy ve arkadaşları tarafından 1998 yılında yapılmıştır. Psikiyatrik hastalığı olan bireylerle yapılan çalışmada, ölçeğin Cronbach alfa iç tutarlılık katsayısının 0.93 olduğu belirlenmiştir. Ölçeğin madde toplam puan korelasyon katsayısı ise 0.45-0.72 arasında değişirken; test-tekrar test güvenirlik katsayısı ise $r=0.57$ olarak bulunmuştur. Ölçeğin Otomatik Düşünceler Ölçeği ile korelasyonu 0.41( $\mathrm{p}<0.001)$, Beck Umutsuzluk Ölçeği ile 0.34 ( $p<0.01)$, Beck depresyon Ölçeği ile 0.46 ( $p<0.001$ ) olarak belirtilmiştir. 


\section{Verilerin Toplanması}

Araştırmaya katılacak öğrencileri belirlemek amacıyla Beck ve arkadaşları tarafından geliştirilen Beck Anksiyete Ölçeği kullanılmıştır. Ölçek İstanbul'da psikoloji bölümünde öğrenim görmekte olan ikinci ve üçüncü sınıfa devam eden $46 \mathrm{kız}, 18$ erkek, toplam 64 öğrenciye araştırmacı tarafından uygulanmıştır. Beck Anksiyete Ölçeği'nden yüksek puan alan 38 öğrenciden çalışmalara katılmaya gönüllü olan 12 kız 6 erkek toplam 18 öğrenci belirlenmiştir. Şubat 2016 - Nisan 2016 tarihleri arasında toplam sekiz hafta süreyle, hazırlanan program katılımcılara uygulanmıştır. Oturumlar başladıktan sonra katılımcılara çalışmanın içeriği ve izlenecek yöntem hakkında bilgi verilmiştir. Program 18 katılımcı ile başlamış ve iki öğrencinin oturumlara ve değerlendirmelere katılmaması nedeniyle, verilerin analizi 16 öğrenci üzerinden yapılmıştır. Oturumlar haftada bir kez 90 dakika süreyle uygulanmıştır. Çalışma okul saatleri dişında aynı gün 16.30-18.00 arasında yürütülmüştür. Programın uygulamasının ardından çalışma grubunda yer alan öğrenciler Beck Anksiyete Ölçeği'ni bir kez daha doldurmuşlardır.

\section{İşlem}

Bilinçli Farkındalık Temelli Bilişsel Terapi Programının Hazırlanması ve Uygulanması: Araştırma, ön-test ve son-test uygulamaları arasında gerçekleştirilen bireylerin kaygı düzeylerini olumlu yönde değişmelerine yönelik sekiz oturumluk Bilinçli Farkındalık Temelli Bilişsel Terapi Programı'dır. Bu çalışmada; ayrışma (defuzyon), şimdiye odaklanma, yargısızlık ve kabullenme gibi farkındalık becerilerinin yanı sıra psikoeğitim, gevşeme eğitimi, kendine yönerge verme, bilişsel yeniden yapılandırma, sosyal beceri eğitimi gibi bilişsel teknikler uygulanmıştır. Program, araştırmacı tarafından birçok kaynaktan yararlanılarak geliştirilmiştir (Demir, 2014; Demir, 2015a; Demir, 2015b; Özyeşil ve Ögel, 2013).

Her oturumda verilecek bilgiler, yapılacak alıştırmalar ve oturum sonunda verilecek ödevler belirlenmiştir. Her oturumun amacı katılımcıların kazanması beklenen hedef düşünce, duygu ve davranışlar belirlenerek hazırlanmıştır. Ayrıca, tüm üyelerin bir sonraki grup oturu- 
muna kadar o oturumda üzerinde durulan bilinçli farkındalık (mindfulness) egzersizlerinin günlük yaşama uygulamasına ve her oturumun başında bu yaşantıların paylaşılmasına çalışılmıştır.

I. Oturum: Grup üyeleri "hoş geldiniz" diyerek güler yüzle karşılandı. Grup üyeleriyle birlikte kurallar belirlendi. Devam, gizlilik, alıştırmalara ve ödevlere katılım belirlenen kurallar içindeydi. Grup üyelerinden geribildirimler alınarak ve de ön testin uygulaması ile birlikte programın içeri ile ilgili bilgi verildi.

II. Oturum: Grup üyelerine düşünce, duygu ve davranış arasındaki ilişkinin önemi çeşitli örneklerle anlatıldı. Nefes egzersizine başlamak için katılımcların rahat bir şekilde oturmaları sağlandı. Nefes alışınızın farkında olarak kendinizi an'a hapsedin ve başlayın. Bedeninizin her parçasını hissedin ve oradaki yaşamı hissetmenin nasıl olduğunun farkında olun" yönünde telkinler verildi. Egzersizin sonunda katılımcılara dikkatleri nefeslerinde iken zihinlerini meşgul eden düşünceler soruldu. Katılımcıların birçoğu, dikkatini nefese verdiğinde düşüncelerinin yok olduğu yönünde cevap verdiler.

III. Oturum: Grup üyelerine şimdi ve burada olmanın, an'da yaşamanın önemi açıklandı. Olumsuz duygu ve düşüncelerle baş edebilmek için nefes egzersizleri uygulatıldı ve uygulanan egzersizler ev ödevi verildi.

IV. Oturum: Grup üyelerinde olumsuz duygulara yol açan 'olumsuz otomatik düşünceler' hakkında bilgi verildi ve bu olumsuz otomatik düşüncelerin kendilerinde var olup olmadığ1 sorgulandı. Olumsuz otomatik düşüncelerin tespitine dair ev ödevi verildi.

V. Oturum: Çalışmaya grup üyelerine beden farkındalığının kendi bedenleriyle ilişkilerini güçlendireceği, zihnin odaklanma yetisini güçlendirdiği ve gevşemeyi sağladığı konusunda bilgi verildikten sonra;

Fiziksel beden farkındalığ 1

Nefes ile beden farkındalığını birleştirme

Hissederek nefes alma

şeklinde 3 adım olan beden farkındalığı egzersizi uygulandı. 
VI. Oturum: Grup üyelerinin olumsuz otomatik düşüncelerle nasıl baş edeceklerini fark etmeleri amaciyla bu düşünceleri destekleyen ve desteklemeyen kanıtların olup olmadığı üzerinde çalışıldı. Çalışmaya daha sonra katılımcılara beden farkındalığı ile nefes farkındalığını birleştirme çalışmaları yapıldı.

VII. Oturum: Oturum sirasında katılımcların, kaygi hakkında bilgi edinmeleri ve baş etmede yapılabilecekler hakkında bilgi edinmeleri hedeflenmektedir. Grup üyelerine daha sonra kaygilı durumlarda kullanabilecekleri "Tek bir şey düşünme" alıştırması uygulatıldı. Önce birkaç farkında nefes alıp vermeleri sağlandı. Son günlerde onları üzen herhangi bir düşünce ile zihinlerini meşgul etmeleri istendi. Ardından yakınlarındaki bir cismi seçip o cisme odaklanmaları istendi. Aşağıdaki sorulara yanıt bulmaya çalışırken bu esnada zihinlerini olumsuz düşünce ile meşgul etmeleri istendi.

Bu cismin yüzeyi nasıl?

Düz mü, pürtüklü mü?

Ne renkte? Hangi renk tonları var?

Parlak mi, mat mi?

Yumuşak mi sert mi?

Büyüklügü ne kadar?

Isısı nasil?

A ğırlığı ne kadar?

VIII. Oturum: Katılımcıların kendilerini yargılamış oldukları özellikleri kabullenmeye yönelik çalışma yapıldı. Alıştırmadan çıkan sonuç; her bir katılımcının, kendilerininkine benzer yaşam deneyimleri karşısında benzer düşünceler geliştirdikleri yönünde idi. Son oturum olan sekizinci oturumda genel bir özet yapılmıştır. Katılımcılardan ilk oturum ile son oturum arasında kendilerindeki değişimlere dair geri bildirimler alındıktan sonra son test uygulandı.

\section{Verilerin Analizi}

Ölçme araçları ile toplanan verilerin çözümlenmesinde; araştırmanın genel amacı çerçevesinde cevapları aranan amaçlara yönelik olarak 
toplanan veriler SPSS programına girilmiştir ve veriler üzerinde gerekli istatistiksel çözümlemeler için SPSS 16.0 paket programından yararlanılmıştır. Literatürde denek sayısının düşük olduğu durumlarda dağılımın normal olmayacağı ve bu nedenle parametrik olmayan testlerin kullanılması önerilmektedir (Drew, Hardman ve Hard, 1996). Bu nedenle, araştırmada verilerin normal dağılım göstermemesi ve denek sayısının azlığ 1 da dikkate alınarak parametrik olmayan testlerin kullanılması tercih edilmiştir. Öntest - sontest puan karşılaştırmalarında, puanlar arasındaki farkın anlamlılı̆̆ını test eden parametrik olmayan istatistiksel tekniklerden biri olan Wilcoxon İşaretli Sıralı Testi kullanılmıştır.

\section{Bulgular}

Bu bölümde araştırmada elde edilen bulgular yer almaktadır. Araştırmada bilinçli farkındalık temelli bilişsel terapi programının üniversite öğrencilerinin kaygı düzeylerine etkisi incelenmiştir.

Tablo 2: Çalışma Grubundaki Öğrencilerin Beck Anksiyete Ölçeği (BAÖ) Öntest ve Sontest Puan Ortalamaları

\begin{tabular}{clll}
\hline Kayg1 & $\mathbf{N}$ & Ortalama & Ss \\
\hline Ön Test & 16 & 21,37 & 8,913 \\
Son Test & 16 & 18,25 & 11,054 \\
\hline
\end{tabular}

Tablo-2 incelendiğinde katılımcıların kaygı son test puan ortalamaları $\bar{X}$ $=18,25$, ön test puan ortalamaları $\bar{X}=21.37$ olduğu görülmektedir. Öntest - sontest puan ortalamaları arasında anlamlı bir farkın olup olmadığı Wilcoxon işaretli sıralar testi ile analiz edilmiş, sonuçlar tablo 3' de verilmiştir.

Tablo 3: Beck Anksiyete Ölçeği (BAÖ) Öntest - Sontest Wilcoxon Işsaretli Stralar Testi Sonuçları

\begin{tabular}{lllllll}
\hline & Sıra İşaretleri & $\mathbf{n}$ & Sira ortalaması & Sira toplamı & $\mathbf{z}$ & $\mathbf{p}$ \\
\hline \multirow{3}{*}{ Kayg1 } & Negatif Sıra & 9 & 8,50 & 76,50 & $-2,170$ & \multirow{2}{*}{030} \\
& Pozitif Sıra & 4 & 3,62 & 14,50 & & \\
& Eşit & 3 & & & & \\
\hline
\end{tabular}

${ }^{*}$ Negatif siralar temeline dayalı 
Katılımcıların öntest - sontest puanları arasında anlamlı bir farklılaşma olduğu bulunarak $(\mathrm{z}=,-2,170 \mathrm{p}<.05)$ Tablo 3'de gösterilmiştir.

\section{Tartışma}

Bilinçli farkındalık temelli bilişsel terapi programına katılan öğrencilerin program öncesi kaygı puan ortalamaları ile program sonrası kaygı puan ortalamaları arasında anlamlı düzeyde farklılaşma olup olmadığı sınanmıştır. İstatistiksel analiz sonucu terapi programının üniversite öğrencilerinin kaygı düzeylerini azaltmada etkili olduğu söylenebilir.

Bilinçli farkındalık temelli bilişsel terapi programı hazırlanırken, programa katılan öğrencilerin kaygılarını bilişsel öğeler çerçevesinde ele alınması, kaygıya yol açan olumsuz otomatik düşüncelerin yerine alternatif rasyonel düşüncelerin konulması, beden, duygu ve düşüncelerin farkına varma, her türlü duygu ve düşünceyi olduğu gibi yargılamadan, bastırmadan ve olumsuz yaşam deneyimlerinin nedenini sorgulamak yerine onları olduğu gibi kabullenmeleri kaygı düzeylerini azaltacağı beklentisinden hareket edilmiştir.

Farkındalık temelli terapi; bireylerin "şu anda, şu dakika"daki yaşantılarına yoğunlaşarak düşünce ve duygularını yargılamadan ve yok saymadan kabul etmelerini amaçlamaktadır. Bilinçli farkındalık temelli bilişsel terapi programının, katılımcıların duygu düzenlenmesi, eşduyum yeteneğinin ve bilişsel esnekliğin artması gibi olumlu etkilerin artırdığı gözlemlenmiştir. Böylece bireylerin acı veren düşünce ve duygularla etkin bir şekilde baş edebilme becerilerinin geliştiği görülmüştür. Alan yazında yer alan çalışmalara bakıldığında, farkındalık temelli terapilerin bireylerde bilişsel ve duygusal süreçler üzerindeki olumlu etkileri görülmektedir (Baer, 2007; Johnson ve Larson, 1982; Cooper, Frone, Russell ve Mudar, 1995; Mennin, Heimberg ve Fresco 2005).

Literatürde "farkındalık" kapsamında yapılan çalışma bulguları doğrultusunda yüksek bilinçli farkındalık düzeyine sahip bireylerin kayg1, depresyon ve stres düzeylerinin düşük olduğu görülmektedir. Brown ve Ryan (2003) bilinçli farkındalığın psikolojik iyi oluşa katkısını araştırdıkları çalışmalarında bilinçli farkındalığın psikolojik iyi oluşla pozitif yönde ilişkili olduğunu bulmuşlardır. "Bilinçli farkındalık yaratıcılık, dikkat, öğrenme, zihin, beyin, vücut, davranış sağlı̆̆ı, beceri, 
zihinsel sağlık, yaşam kalitesi üzerinde olumlu etkileri olmakla birlikte stres, kaygı ve depresyonu azaltmakta, duygusal farkındalık, duygusal zeka, öz anlayış, pozitif duygu, empati ve yaşam kalitesi değişkenleri ile pozitif yönde, okuma güçlüğü, ruhsal bozukluk, duyguların ifade edilememesi, olumsuz duygu ve internet bağımlılığı ile negatif yönde ilişkili bulunmaktadir" (aktaran Baysal ve Demirbaş, 2012).

Mevcut deneysel kanıtlar farkındalık temelli uygulamarın psikolojik iyi oluşu artırdığını (Astin, 1997), kaygı ve depresyonu azalttığını (Baer, 2003) ve tekrarlamasını engellediğini (Duncan ve Bardacke, 2009) savunmaktadır. Miller, Fletcher ve Kabat-Zinn (1995) tarafından yürütülen bir araştırmada kaygı bozukluğu tanısı almış bireylere sekiz hafta süren farkındalık temelli stres azaltma programı uygulanmıştır. Yapılan analizler çalışma grubundaki katılımcıların kaygı puanlarının anlamlı düzeyde azaldığını göstermiştir. Çalışma sonrasında izlenen değişimin tutarlı olup olmadığını belirleyebilmek amacıyla çalışmanın bitiminden üç yıl sonra izleme ölçümü yapılmıştır. Yapılan izleme ölçümünde kaygı puanlarında bu azalmanın üç yıl süresince devam ettiği gözlenmiştir. Kim ve arkadaşları (2009) panik bozukluğu ve yaygın anksiyete bozukluğu olan hastalarda farkındalık temelli bilişsel terapi programının etkinliğini sınamışlar, program sonucunda istatistiksel olarak kaygı ve depresif belirtilerinin yanında Belirti Tarama Envanteri (SCL-90-R) alt ölçeklerinden obsesif kompulsif ve fobik anksiyete alt ölçekleri de anlamlı ölçüde azalma görülmüş̧ür. Yaygın anksiyete bozukluğu tanısı almış 23 yetişkinin katıldığı farkındalık temelli bilişsel terapi programı sonrası katılımcıların patolojik kaygı ve stres puan ortalamalarında azalma, yaşam kalitesi puan ortalamalarında ise artış saptanmıştır (Craigie, Rees, Marsh, ve Nathan, 2008). Hofmann, Sawyer, Witt ve Oh (2010) yaptıklar1 çalışmada farkındalık temelli terapinin anksiyete tedavisi için umut verici bir yöntem olduğunu rapor etmişlerdir.

Anksiyete tedavisi ile ilgili literatür incelendiğinde neredeyse tamamının bilişsel-davranışçı terapilerin çeşitli türlerini içerdiği görülmektedir. Bilişsel-davranışçı yönelimli terapistler, psikopatoloji ile bilişsel süreçler arasındaki ilişkiye odaklanmaktadırlar (Silverman ve DiGueseppe, 2001). Psikopatolojiyi bilişsel modelle açıklarken yaklaşımın temel vurgularından biri; kaygı bozukluklarında işlevsel olmayan düşüncelerin etkili olduğudur. Alan yazında sözü edilen işlevsel olmayan düşünceler: 
Felaketleştirme (bir olayla ilgili olarak olası en kötü sonucu beklemek), aşırı genelleme (tek bir olumsuz olaydan hareketle genelleme yapmak), kişiselleştirme (bütün olumsuz olaylardan kendini sorumlu tutma) ve seçici soyutlama (bir olayın olumsuz yönüne aşırı odaklanma) dır (Leung ve Wong, 1998).

$\mathrm{Bu}$ çalışmada uygulanan müdahale programı kaygı ile ilgili duygu, düşünce ve davranışların tanımlanmasını, hatalı düşüncelerin değiştirilmesini ve bu düşünceleri destekleyen ve desteklemeyen kanıtların sorgulanması, kaygı ile baş edebilmek için nefes egzersizleri ve farkındalık egzersizlerini içermektedir. Müdahalenin sonunda öğrencilerden grup yaşantısını yazılı olarak değerlendirmeleri istenmiştir. Evlerinde yazarak getirdikleri notlar incelendiğinde önemli bir kısmı benzer sorunları yaşayan bireylerin olduğunu görmenin kendilerini hem şaşırttığını hem de rahatlattığını ifade etmişlerdir. Bir öğrenci "programdan önce ben, benim gibi düşünen bu kadar insan olduğunu bilmiyordum. Benim yaşadığım şeylerin benzerlerini yaşayanların olduğunu ve benim gibi düşünen, hissedenlerin olduğunu bilmek beni rahatlattı" diyerek grup müdahalelerinin en temel avantajı olan "evrensellik" duygusunun bu uygulama sürecinde de oluştuğunu göstermiştir.

Bilinçli farkındalık temelli bilişsel terapi, bireylerin düşüncelerinin sadece bir düşünce; duygularının ise sadece bir duygu olduğunu fark etmelerini sağlar. Bireylerin bu düşünce ve duygularının diğer bireylerin düşünce ve duygularına benzerliği yönündeki farkındalıkları kendilerine yönelik yargılayıcı tutumlarının ve kendine olumsuz odaklanmanın önüne geçecektir (Brown ve Ryan 2003, Zvolensky vd., 2006).

$\mathrm{Bu}$ araştırmanın bazı sınırlılıkları vardır. Araştırma verileri ikinci ve üçüncü sınıfa devam eden üniversite öğrencilerinden elde edildiği için benzer gruplara genellenebilir. Diğer taraftan genellenebilirliği artırmak için geniş örneklem grupları üzerinde yapılacak çalışmalara ihtiyaç vardır. Araştırmada katılımcılar, uygulanan deneysel işlemden bağımsız olarak grup çalışmasına katıldıkları için araştırmacıların kendilerinde olumlu yönde davranış değişikliği beklemelerinden dolayı, bu beklentiyi boşa çıkarmamak için özel bir çaba içine girmelerinden kaynaklanan etkiyi kontrol etmek amacıyla kontrol grubu oluşturulmaması da sinırlılık olarak düşünülmektedir. Çalışmanın önemli sınırlılıklarından biri de araştırmaya katılan bireylerin kaygı düzeylerinin sadece Beck Anksiyete 
Ölçeği ile değerlendirilmiş olması, bir psikiyatrist ve psikolog tarafından bireylerin klinik muayenesinin yapılmamış olmasıdır. Ayrıca çalışma sonucunu etkileyebilecek yaşam koşulları, aile biçimi gibi çeşitli faktörler değerlendirilmemiştir.

Sonuç olarak, bu çalışmada yukarıda belirtilen kısıtlılıklara ve sınırlılıklara rağmen bilinçli farkındalık temelli bilişsel terapi programının üniversite öğrencilerinin kaygı düzeylerini azaltmada etkili olduğu söylenebilir. Araştırmanın bulgularına dayanılarak varılan sonuçlar doğrultusunda aşağıdaki öneriler geliştirilmiştir.

Son yıllarda Türkiye'de bilinçli farkındalık temelli terapilere yönelik ilginin arttığ1 görülmektedir; ancak bu konuda Türkiye'de yapılmış çalışmaların yeterli olmaması elde ettiğimiz sonuçları karşılaştırmamızı sınırlamaktadır. Farkındalık temelli terapilerin etkinliğini değerlendiren yapısal çalışmaların yapılması yararlı olabilir.

Benzer araştırmalar, daha geniş ve farklı özelliklere sahip örneklem grupları üzerinde gerçekleştirilebilir.

İlköğretim, ortaöğretim ve yükseköğretim kurumlarındaki öğrencilerin kaygı düzeylerini azaltmak amacıyla bilinçli farkındalık temelli bilişsel terapi programları yaygınlaştırılabilir.

Uygulanan program oturumlarının daha ayrintılı hale getirilerek ve oturumların sayısı arttırılarak programın kapsamı genişletilebilir. Bu sayede okullarda bir dönem veya bir yıl boyunca uygulanabilecek bir rehberlik çalışması haline getirilebilir.

$\mathrm{Bu}$ araştırmada öğrencilerin kaygı düzeyleri ele alınmıştır. Benzer araştırmalar, öz-yeterlik (genel, mesleki, akademik ve sosyal vb.), depresyon, empatik beceriler, tükenmişlik, duygu düzenleme gibi diğer konularda yapılabilir.

\section{Kaynakça}

American Psychiatric Association. Diagnostic and statistical manual of mental disorders. In: APA, eds. Text Revision. 4th ed. Washington, DC: American Psychiatric Association; 2000: 1-943.

Astin, J. A. (1997). Stress reduction through mindfulness meditation: Effects on psychological symptomology, sense of control, and spiritual experiences. Psychother Psychosom, 66(2), 97-106. 
Baer, R. A. (2003). Mindfulness training as a clinical intervention: A conceptual and empirical review. Clinical psychology: Science and practice, 10(2), 125-143.

Baer, R. A. (2007). Mindfulness, assessment, and transdiagnostic processes. Psychological Inquiry, 18(4), 238-271.

Bao, X., Xue, S., \& Kong, F. (2015). Dispositional mindfulness and perceived stress: The role of emotional intelligence. Personality and Individual Differences, 78, 48-52.

Barlow, D. H. (2002). Anxiety and its disorders: the nature and treatment anxiety and panic. (2.basim). New York: Guilford Press.

Baysal, N. \& Demirbaş, B. (2012). Sınıf öğretmenliği adaylarının bilinçli farkındalıkları ile yansıtıcı düşünme eğilimleri arasındaki ilişkinin incelenmesi. Ĕ̆itim ve Öğretim Araştırmaları Dergisi, 1(4), 12-20.

Beauchemin, J., Hutchins, T. L. \& Patterson, F. (2008) Mindfulness meditation may lessen anxiety, promote social skills and improve academic performance amongst adolescents with learning difficulties. Complementary Health Practise Review, 13(1), 34-45.

Beck A. T., Epstein, N., Brown, G., Steer, R. A. (1988). An inventory for measuring clinical anxiety: Psychometric properties. Journal of consulting and clinical psychology, 56(6), 893.

Beck, A. T. ve Emery, G. (1985). Anxiety disorders and phobias: A cognitive perspective. New York: Basic Books.

Bishop, S. R.,Lau, M., Shapiro, S., Carlson, L., Anderson, N. D., Carmody, J., ... \& Devins, G. (2004). Mindfulness: A proposed operational definition. Clinical psychology: Science and practice, 11(3), 230-241.

Broderick, P.C. \& Metz, S. (2009). Learning to BREATHE: A pilot trial of a mindfulness curriculum for adolescents. Advances in School Mental Health Promotion, 2(1), 35-45.

Brown, K. W., \& Ryan, R. M. (2003). The benefits of being present: mindfulness and its role in psychological well-being. Journal of personality and social psychology, 84(4), 822.

Brown, K. W., Ryan, R. M., \& Creswell, J. D. (2007). Mindfulness: Theoretical foundations and evidence for its salutary effects. Psychological inquiry, 18(4), 211-237.

Carmody, J., \& Baer, R. A. (2009). How long does a mindfulness-based stress reduction program need to be? A review of class contact 
hours and effect sizes for psychological distress. Journal of clinical psychology, 65(6), 627-638.

Cash, M., \& Whittingham, K. (2010). What facets of mindfulness contribute to psychological well-being and depressive, anxious, and stress-related symptomatology?. Mindfulness, 1(3), 177-182.

Cohen-Katz, J., Wiley, S. D., Capuano, T., Baker, D. M., \& Shapiro, S. (2004). The effects of Mindfulness-Based Stress Reduction on nurse stress and burnout: a quantitative and qualitative study. Holistic nursing practice, 18(6), 302-308.

Cooper, M. L., Frone, M. R., Russell, M., \& Mudar, P. (1995). Drinking to regulate positive and negative emotions: a motivational model of alcohol use. Journal of personality and social psychology, 69(5), 990.

Craigie, M. A., Rees, C. S., Marsh, A., \& Nathan, P. (2008). Mindfulnessbased cognitive therapy for generalized anxiety disorder: A preliminary evaluation. Behavioural and Cognitive Psychotherapy, 36(5), 553-568.

Çatak, P. D. , Ögel, K. (2010). Farkındalık Temelli Terapiler ve Terapötik Süreçler. Klinik Psikiyatri, 13, 85, 91.

Demir, V. (2014). Bilinçli farkındalık temelli hazırlanan eğitim programının bireylerin depresyon ve stres düzeyleri üzerine etkisi, Yayınlanmamış Yüksek Lisans Tezi, İstanbul Arel Üniversitesi.

Demir, V. (2015). Bilinçli Farkındalık Temelli Kognitif Terapi Programının Bireylerin Depresif Belirti Düzeyleri Üzerine Etkisi. Psikoloji Çalışmaları Dergisi, 35(1), 15-26.

Demir, V. (2015). Görme Engellilerde Depresif Belirtilere Yönelik Bilinçli Farkındalık Temelli Bilişsel Terapi Programının Etkililiği. Nesne, 3(6), 77- 93.

Drew, C. J., Hardman, M. L., \& Hart, A. W. (1996). Designing and conducting research: Inquiry in education and social science. Allyn \& Bacon.

Duncan, L. G., Coatsworth, J. D., \& Greenberg, M. T. (2009). A model of mindful parenting: Implications for parent-child relationships and prevention research. Clinical child and family psychology review, 12(3), 255-270.

Germer, C. K., Siegel, R. D. ve Fulton, P. R. (2005). Mindfulness and psychotherapy. (1.basim). New York: Guilford. 
Gross, C. R., Kreitzer, M. J., Thomas, W., Reilly-Spong, M., Cramer-Bornemann, M., Nyman, J. A., ... \& Ibrahim, H. N. (2010). Mindfulnessbased stress reduction for solid organ transplant recipients: a randomized controlled trial. Alternative therapies in health and medicine, 16(5), 30.

Hayes, S. C.,Luoma, J. B., Bond, F. W., Masuda, A., Lillis, J. (2006). Acceptance and Commitment Therapy: Model, processes and outcomes. Behaviour Research and Therapy, 44(1), 1-25.

Hofmann, S. G., Sawyer, A. T., Witt, A. A., \& Oh, D. (2010). The effect of mindfulness-based therapy on anxiety and depression: A meta-analytic review.Journal of consulting and clinical psychology, 78(2), 169.

Huppert, F. A. \& Johnson, D. M. (2010). A controlled trial of mindfulness training in schools; the importance of practice for an impact on well-being. The Journal of Positive Psychology, 5(4), 264-274.

Johnson, C., \& Larson, R. (1982). Bulimia: An analysis of moods and behavior. Psychosomatic Medicine, 44(4), 341-351.

Kabat-Zinn, J. (2003). Mindfulness-based interventions in context: past, present, and future. Clinical psychology: Science and practice, 10(2), 144-156.

Kabat-Zinn, J. (2005). Coming to our senses: Healing ourselves and the world through mindfulness. Hachette UK.

Karasar, N. (2014). Bilimsel araştırma yöntemi. (26.baskı). Ankara Nobel Yayınevi.

Kemper, K., Bulla, S., Krueger, D., Ott, M. J., McCool, J. A., \& Gardiner, P. (2011). Nurses' experiences, expectations, and preferences for mind-body practices to reduce stress. BMC complementary and alternative medicine, 11(1), 1.

Kim, Y. W., Lee, S. H., Choi, T. K., Suh, S. Y., Kim, B., Kim, C. M., ... \& Song, S. K. (2009). Effectiveness of mindfulness-based cognitive therapy as an adjuvant to pharmacotherapy in patients with panic disorder or generalized anxiety disorder. Depression and anxiety, 26(7), 601-606.

Kristofersson, G. K. (2012). The effects of a mindfulness based intervention on impulsivity, symptoms of depression, anxiety, experiences and quality of life of persons suffering from substance use disorders and traumatic brain injury (Doctoral dissertation, University of Minnesota). 
Leung, P. W., \& Wong, M. M. (1998). Can cognitive distortions differentiate between internalising and externalising problems?. Journal of Child Psychology and Psychiatry, 39(2), 263-269.

Liehr, P. \& Diaz, N. (2010). A pilot study examining the effect of mindfulness on depression and anxiety for minority children. Archives of Psychiatric Nursing, 24(1), 69-71.

Mackenzie, C. S., Poulin, P. A., \& Seidman-Carlson, R. (2006). A brief mindfulness-based stress reduction intervention for nurses and nurse aides. Applied Nursing Research, 19(2), 105-109.

Matchim, Y., Armer, J. M., \& Stewart, B. R. (2011). Effects of mindfulnessbased stress reduction (MBSR) on health among breast cancer survivors. Western Journal of Nursing Research, 33(8), 996-1016.

Mennin, D. S., Heimberg, R. G., Turk, C. L., \& Fresco, D. M. (2005). Preliminary evidence for an emotion dysregulation model of generalized anxiety disorder. Behaviour research and therapy, 43(10), 12811310.

Miller, J. J.,Fletcher, K., Kabat-Zinn, J. (1995). Three-year follow-up and clinical implications of a mindfulness meditation-based stres reduction intervention in the treatment of anxiety disorders. General hospital psychiatry, 17(3), 192-200.

Napoli, M., Krech, P. R. \& Holley, L. C. (2005). Mindfulness training for elementary school students. Journal of Applied School Psychology, 21(1), 99-125.

Ohman, A. (2000). Fear and anxiety: Evolutionary, cognitive, and clinical perspectives. New York: The Guilford Press.

Özyeşil, Z. (2011). Özanlayış ve Bilinçli Farkındalık. Ankara: Maya Akademi Yayıncilik.

Özyeşil, Z., \& Ögel, K. (2013). The Effects of a Mindfulness and Acceptance Based (Education) Program on University Students' Perceived Stress and Test Anxiety. Oral presentation. In First International Conference on Mindfulness (ICM), Sapienza University of Rome, May (pp. 8-12).

Peterson, L. G., \& Pbert, L. (1992). Effectiveness of a meditation-based stress reduction program in the treatment of anxiety disorders. Am J Psychiatry, 149(7), 936-943. 
Pinquart, M., \& Teubert, D. (2010). A meta-analytic study of couple interventions during the transition to parenthood. Family Relations, 59(3), 221-231.

Schonert-Reichl, K. A. \& Lawlor, M. S. (2010). The effects of a mindfulnessbased education program on pre-and early adolescents' well-being and social and emotional competence. Mindfulness, 1(3), 137151.

Semple, R. J., Lee, J., Rosa, D., \& Miller, L. F. (2010). A randomized trial of mindfulness-based cognitive therapy for children: Promoting mindful attention to enhance social-emotional resiliency in children. Journal of Child and Family Studies, 19(2), 218-229.

Siegel, R. D., Germer, C. K., \& Olendzki, A. (2009). Mindfulness: What is it? Where did it come from?. In Clinical handbook of mindfulness (pp. 1735). Springer New York.

Silverman S. \& Digiuseppe R. (2001). Cognitive-Behavioral constructs and children's behavioral and emotional problems. Journal or RationalEmotive \& Cognitive-Behavior Therapy, 19(2), 119-134.

Smith, J. E., Richardson, J., Hoffman, C., \& Pilkington, K. (2005). Mindfulness-Based Stress Reduction as supportive therapy in cancer care: systematic review. Journal of advanced nursing, 52(3), 315-327.

Stahl, S. M. (2013). Stahl's essential psychopharmacology: neuroscientific basis and practical applications. Cambridge university press.

Tsang, S. C. H., Mok, E. S. B., Lam, S. C., \& Lee, J. K. L. (2012). The benefit of mindfulness-based stress reduction to patients with terminal cancer. Journal of clinical nursing, 21(17-18), 2690-2696.

Ulusoy, M., Şahin, N. ve Erkmen, H. (1998). Turkish version of the Beck Anxiety Inventory: Psychometric properties. Journal of Cognitive Psychotherapy, 12(2), 163-172.

Visted, E., Vøllestad, J., Nielsen, M. B., \& Nielsen, G. H. (2015). The impact of group-based mindfulness training on self-reported mindfulness: a systematic review and meta-analysis. Mindfulness, 6(3), 501-522.

Vøllestad, J., Sivertsen, B., \& Nielsen, G. H. (2011). Mindfulness-based stress reduction for patients with anxiety disorders: evaluation in a randomized controlled trial. Behaviour research and therapy, 49(4), 281-288. 
Wang, Y., \& Kong, F. (2014). The role of emotional intelligence in the impact of mindfulness on life satisfaction and mental distress. Social Indicators Research, 116(3), 843-852.

Whitebird, R. R., Kreitzer, M. J., \& O'Connor, P. J. (2009). Mindfulnessbased stress reduction and diabetes. Diabetes spectrum: a publication of the American Diabetes Association, 22(4), 226.

Whitebird, R. R., Kreitzer, M., Crain, A. L., Lewis, B. A., Hanson, L. R., \& Enstad, C. J. (2012). Mindfulness-based stress reduction for family caregivers: a randomized controlled trial. The Gerontologist, 53(4), 676-686.

Witek-Janusek, L., Albuquerque, K., Chroniak, K. R., Chroniak, C., Durazo-Arvizu, R., \& Mathews, H. L. (2008). Effect of mindfulness based stress reduction on immune function, quality of life and coping in women newly diagnosed with early stage breast cancer. Brain, behavior, and immunity, 22(6), 969-981.

Yook, K., Lee, S. H., Ryu, M., Kim, K. H., Choi, T. K., Suh, S. Y., ... \& Kim, M. J. (2008). Usefulness of mindfulness-based cognitive therapy for treating insomnia in patients with anxiety disorders: a pilot study. The Journal of nervous and mental disease, 196(6), 501-503.

Zvolensky, M. J., Solomon, S. E., McLeish, A. C., Cassidy, D., Bernstein, A., Bowman, C. J., \& Yartz, A. R. (2006). Incremental validity of mindfulness-based attention irelation to the concurrent prediction of anxiety and depressive symptomatology and perceptions of health. Cognitive behaviour therapy, 35(3), 148-158.

\section{Kaynakça Bilgisi / Citation Information}

Demir, V. (2017). Bilinçli Farkındalık Temelli Bilişsel Terapi Programının Üniversite Öğrencilerinin Kaygı Düzeylerine Etkisi, OPUS Uluslararası Toplum Araştırmaları Dergisi, 7(12), 98-118. 